DOI: 10.1515/ausfm-2016-0011

\title{
Immersion at the Intersection of Technology, Subjectivity and Culture: An Analysis of Silent Hill 2
}

\author{
Andrei Nae \\ University of Bucharest (Romania) \\ E-mail: andrei.nae@lls.unibuc.ro
}

\begin{abstract}
This paper inspects the concept of immersion in video games as a gradient category resulting from the degrees of interactivity and immediacy. By factoring in the objective technological affordances of media, as well as the subjective impression that these affordances help create, and the culturally constructed nature of gameplay experience, I argue that high degrees of interactivity and immediacy are not achieved solely by giving the player more freedom of action, and, respectively, by inflecting the content of the narrative as little as possible with the medium's specific narrative affordances. Quite on the contrary, it is necessary that freedom be limited and content be manipulated for the video game to have high degrees of narrativity and playability, thus ensuring player engagement. In the absence of player engagement, the mediated nature of gaming experience becomes obvious and the level of immersion decreases. In the last section, I explore the relationship between video games and film and point out the consequences the remediation of film has regarding the level of immediacy. ${ }^{1}$
\end{abstract}

Keywords: immersion; immediacy; interactivity; remediation; Silent Hill 2; first person shooters; third person shooters.

For all its widespread use, immersion is a term that is still the subject of debate in the academia and a consensus with regards to what the concept entails remains to be reached. While far from attempting to establish once and for all what immersion means, I hope that, by factoring in research in the fields of post-classical narratology, media studies, and game studies, I come up with a view on immersion that accounts for the objective specific technological medium affordance, the subjective impression of being there, and the cultural

1 Thisworkwasco-financed from theEuropeanSocialFund throughSectoralOperationalProgramme Human Resources Development 2007-2013, project number POSDRU/187/1.5/S/155559, Competitive Multidisciplinary Doctoral Research in Europe. 
constructedness of the impression of being there. As my argument unfolds I shall refer to the survival horror video game Silent Hill $2^{2}$. The purpose of the analysis is twofold: on the one hand, I intend to show the relevance of the concept of immersion for the production of video games, and on the other hand, I intend to use the video game in order to enhance our understanding of immersion by looking at aspects of interactivity and immediacy.

\section{What is Immersion?}

In his book In-Game: From Immersion to Incorporation, Gordon Calleja (2011) traces the complicated history of immersion from its initial purely technological understanding as the ability to remotely, yet actively influence the (fictional) world, to the more recent and more encompassing definitions that regard immersion as the psychological effect of "being there" created by the technonarrative affordances of the particular media. Today, immersion is roughly conceived as the illusion of presence and, optionally, the ability to influence the fictional world. Although not necessarily using the word immersion, recent approaches to narrative theory have described interpreter involvement in a similar manner. Coming from a cognitive narrative background, David Herman, for instance, argues that narrative world-making means co-inhabiting the same world with the author $(2012,14)$. Prior to this, attempting to explain how the reader interacts with an "empty centre" narrative (i.e. "a reflector-mode representation of narrative events or existents in the absence of any internal focalizer or reflector figure, hence from the point of view of an 'empty (deictic) center'" [Jahn 2005, N3.2.5]), Monika Fludernik asserted that these narratives are immersive because the storyworld is mediated by an empty centre of subjectivity whose perception of the storyworld is in keeping with viewing script that humans share. Therefore, the reader is given the illusion that it is he/ she who is actually seeing the storyworld $(1993,383)$.

My thesis endorses the more generous definition of immersion and maintains that the technology of immersion heightens the psychological impression of being immersed in another world. Understanding immersion presupposes looking at its two intimately related dimensions: immediacy and interactivity. While the former is the fundamental condition of immersion, and, arguably in non-ergodic, non-interactive media, immediacy and immersion are one and the same thing, in the case of ergodic (Aarseth 1998) and interactive media, the level of immersion

2 Konami Computer Entertaiment. 2001. Silent Hill 2 Director's Cut. 
should increase with the level of interactivity. Immersion in this paper is a variable, which in itself is the sum of two variables: immediacy and interactivity.

Probably the most popular narrative medium which thrives on immediacy and interactivity is the video game. In my analysis of immersion in video games I conceptualize immersion as a gradient category. Because video games are considered both games and narratives (Ryan 2006, 181-203), my analysis of immersion, i.e. of immediacy and interactivity, will dovetail with aspects of narrativity. In what follows, I shall investigate the survival horror classic, Silent Hill 2. My analysis will be divided into three parts: I will be looking at aspects of interactivity and then at aspects of immediacy, with a last section dealing with an issue intimately connected with immediacy, namely that of remediation. Before commencing, I would like to mention from early on that the separate treatment of interactivity and immediacy does not suggest that the two dimensions of immersion are isolated from one another. Quite on the contrary, the discussion of either of the two will always imply the other.

\section{Interactivity}

According to Marie-Laure Ryan, interactivity is a gradient category whose level can be established by cross matching the four categories of interactivity based on two criteria: the position of the player inside or outside the gameworld and the ability or lack thereof to influence the gameworld (2006, 107-120). This way we get internal or external interactivity and ontological or exploratory interactivity. In the case of Silent Hill 2, we are dealing with a case of internal ontological interactivity, which is the highest degree of interactivity. In the game the player controls James Sunderland, who has to make his way through a ghost town filled with monsters resembling his and the other characters' traumatic memories. James also has to solve a lot of puzzles, an activity reminiscent of adventure video games such as Myst. ${ }^{3}$

What is highly relevant for the ontological aspect of interactivity in Silent Hill 2 is the influence that the player's acts can have on determining the ending. Silent Hill 2 has six endings that can be triggered by choosing a particular narrative branch throughout the game. Yet, what is interesting is that these narrative nodes are concealed and the person playing Silent Hill 2 for the first time without knowledge of the game design is likely to be unaware of the decision making points.

A deeper insight into the issue of the plot is required here. Like most horror themed action adventure games, Silent Hill 2 has a rigid scripted story that leaves 
the player room for narrative input only in-between narrative nodes which are usually marked by cinematic cut-scenes. You can dodge or kill monsters, take the short or long way, discover the chainsaw or not, but progress depends on the player's reaching a particular check point which pushes the narrative forward. However, Silent Hill 2 is, or better yet, was different from most other video games released around 2001 in that the actions of the player in-between two nodes also determine the selection of a particular pre-established narrative script.

How can we relate this aspect of interactivity to immediacy? In real life we obviously have more freedom than in a video game such as Silent Hill 2. The limitations imposed by the game mechanics on the player can lead to an awareness of the mediation. When experiencing fictional worlds, individuals extrapolate their knowledge about the real world in order to make sense of it (Ryan 1991, 4860). In Silent Hill 2, the protagonist you control is an average person who should be able to do anything an average human being can do. Yet the rules embedded in the game code allow the enaction of only a small part of the movements a human being is capable of in the real world. The relation between fiction and rules is very well documented by Jesper Juul $(2014,175)$, who claims that the content of a video game can be split into the following three categories:

1. "Fiction implemented in rules:" we expect the keys in Silent Hill 2 to open doors, we expect knives to inflict damage;

2. "Fiction not implemented in games:" you cannot jump, although one would expect a human being to be able to jump;

3. "Rules not explained by fiction:" James Sunderland jumps down deep crevices, is thrown from the rooftop of the hospital by Pyramid Head, can get pierced several times by Pyramid Head's spear and, nevertheless, survives.

Judging by the logic of immediacy, it would be desirable that the rules implement as much of the fiction as possible, i.e. give the player a very high degree of freedom in terms of movements, gestures and so on, and limit as much as possible the rules that are not explained by fiction. However, such an attempt does have its downside. Indeed, the limited control options and plot developments are so unlike real life that they highlight the artificiality of the video game, thus making it hypermedial. Nonetheless, the small number of available movements, and the pre-scripted nature of the plot in Silent Hill 2 and other video games ensure that the game entertains a high degree of playability and narrativity ${ }^{4}$ which then

4 Post-classical narrative theory has relinquished rigid definitions of narrative and, instead of 
maintain a strong ludic and narrative engagement with the game. Were this not the case, the game would become boring. In the absence of player engagement, the mediated nature of gaming experience is highlighted and immediacy turns to hypermediacy.

On a microlevel, the fact that shackled old wooden doors cannot simply be brought down with the metal pipe James Sunderland wields throughout the game, or that their locks cannot be shot open with the gun can thwart the medium's transparency. Nevertheless, if the game allowed this, its ludic part would be greatly impaired. If getting through were that simple and no longer required finding the right key, the adventure side of Silent Hill 2 would be significantly diminished. Moreover, "in a well-known formulation, Bernard Suits defines games as being about attaining a goal using the 'less efficient means' available. For example, the high jump would be easier if we could use a ladder, a race would be easier if we could cut across the tracks, and soccer would be easier if we could pick up the ball. 'To stick a game in there,' as Lantz was quoted saying, is fundamentally about reducing the number of possibilities available to the player in order to make a game" (Juul 2014, 189).

So, while the logic of immediacy would push towards an ever greater number of possibilities, the logic of playability, which is fundamental for player engagement, requires the exact opposite, namely, the limitation of possibilities. Notwithstanding the apparent contradiction between immediacy and playability, in fact, a high degree of playability can help maintain the illusion of transparency by ensuring a strong engagement of the player with the fictional interactive world of the video game.

Of particular importance to achieving the balance between immediacy and playability is the technological medium employed by video games. Due to their digital nature, video games can easily enforce their rules on the player, unlike more traditional games, where the players can negotiate the rules or where a player can easily choose to break them. In this respect, video games are different from other games in what concerns the player's lusory attitude.

According to Bernard Suits, obeying the rules of a game is fundamental for the ludic nature of the game-activity as such $(1978,24)$. Players choose to obey the rules in order to make the game possible, in spite of the fact that these rules make the achievement of the goal more complicated. The gratuitous submission to the

trying to establish what a narrative is or is not, narratologists speak of degrees of narrativity (Fludernik 1996, Ryan 2006, Prince 2008, Herman 2009). By relying on prototype theory, these scholars attempt to identify core features of narrativity that can be shared to certain degrees by cultural products that claim to be narratives. 
rules of the game is called by Suits the player's lusory attitude $(1978,35)$. In a traditional game, the player has to make an effort of volition to commit himself to the rules and resist the temptation to cheat when in danger of losing. In video games, the lusory attitude is no longer an essential element of the ludic nature of the game because, due to technological constraints, the player can no longer cheat, or, in any case, cheating is far more complicated, i.e. the player would have to be a programmer who can develop a patch that can give him/her more possibilities than originally intended by the game developer. As a result, a video game will always be a game because its rules cannot be broken from within. Even cheats, i.e. codes which create an apparently unfair advantage for the player upon insertion, are rules in themselves, albeit hidden, written in the game code by the developers. Consequently, inserting a cheat is not essentially tantamount to breaking a rule since the cheat in video games is itself a rule.

When playing Silent Hill 2, the player cannot but obey the very strict rules imposed by the game. Although the anti-gameplay design philosophy of classical survival horror video games (Nae, forthcoming) may determine the player to cheat, the digital medium prevents the player from breaking the rules, thus ensuring the maintenance of the ludic nature of Silent Hill 2. Since the player can in no way break the rules and, thus, dilute the ludicity of the video game, his/ her only option is to quit the video game altogether.

On a macro-level, we encounter a similar discrepancy between the demands of immediacy and, in this case, narrativity. The fact that the player's actions can have a limited bearing on the outcome and that the outcome, as well as the succession of events, is pre-scripted, is indeed in contradiction with our expectations about the fictional world - expectations informed by our knowledge of the real world. However, the pre-scripted nature of the plot ensures that the narrative design of the video game is maintained. If in Silent Hill 2 James Sunderland could simply leave whenever he wanted by retracing his steps back to the car, he would not meet Maria, he would not face his traumas, we would not know what really happened to Mary, all in all, we would not have a story. Once again, having a definite narrative profile ensures the player's narrative engagement, which then sustains the illusion of transparency craved by media.

A game designer is coerced to choose the lesser of two evils: either limit the possibilities and stress how little freedom one has in a game which pursues a particular narrative profile, or give the player a great amount of freedom by loosening the script as much as possible, and, as result, lose the narrative design and bore the player, which, in the end, also leads to hypermediacy. Therefore, 
the degree of immersion of a video game depends on how well game designers manage to balance the freedom of choice typical of real life and the narrative constraints that maintain the narrative design of the video game.

\section{Immediacy}

After focusing on interactivity, it is time to move the focus to immediacy. First, what is immediacy? Immediacy is the desire of media to erase their mediation, to give the audience the impression that they are experiencing the authentic thing (Bolter and Grusin 1999, 6). In the case of fictional narratives, instead of the real thing, the goal is to trick the audience into believing they are experiencing "the world assumed to be actual within the narrative" (Herman 2009, 122). The counterpoint of immediacy is hypermediacy, which seeks not to erase mediation, but to highlight it (Bolter and Grusin 1999, 31).

Intimately related to the issue of immediacy is that of narration. Each narrative has a narrator who manipulates the techno-narrative affordances of the medium in order to convey the story in its plot form. ${ }^{5}$ The more manipulations the story undergoes to obtain its plot form, the more obvious the narrator and the medium are, thus obtaining hypermediacy. Conversely, the fewer manipulations the story undergoes, the less obvious the narrator and the medium become, thus obtaining immediacy. In order to illustrate this idea, let us focus on the issue of temporality. It is an established fact in narrative theory that narratives feature a sjuzet and a fabula, also known as plot and story, which are linked to discourse time and story time, respectively (Brooks 1992, 12-13). Discourse time is a clear example of artificiality because it highlights the mediated nature of the narrative through

5 An important digression is required here. The last ten years have witnessed a growing body of literature coming from the fields of adaptation and media studies that have highlighted the importance of medium specificity. There is a wide consensus among scholars in these fields that each medium has a set of narrative affordances provided by their technology that are used to convey the content of a narrative (Hutcheon 2006; Ryan 2006). Drawing on David Herman, I would like make a step further and attribute the employment of these narrative affordances to the narrator. This is due to the fact that the narrator's narrational acts, i.e. what the narrator chooses to represent from the storyworld and the way in which he/she represents, are construed as if they were the gestures of a singular human-like entity, whose acts have a particular motivation and pursue a particular goal. Making sense of a narrative presupposes making inferences about the intentions, beliefs and desires that motivate the narrator's narrational acts (Herman 2012, 44). Narrative cultural products that are the result of collective authorship, i.e. the product receives the input of more than one creator of content, are no exception to this process of reception. Because of our theory of mind and narrative schemata, we need a personal teller to convey the narrative to us (Fludernik 1993, 440). Even if there are clearly more than one tellers involved, reception undergoes the same inferentional process that is based on making sense of the narrational acts of only one narrator (Herman 2012, 48-49). 
flashbacks, anticipation, contractions and so on. While some media are better at hiding the manipulation of temporality than others (see film cuts vs. comic book panels), it goes without saying that time manipulation exists in all narrative media, including drama (Hogan 2014, 50-66).

If the gap between discourse time and event time, or plot and story, is a trait of artificiality that flaunts the immediate and, I daresay, immersive character of narratives, then bridging the gap between the two would seem the evident solution to enhance immediacy and immersion. Unfortunately, the presupposed higher degree of immediacy and immersion would come at a cost, namely that of narrativity and playability (in the case of video games). Moreover, as argued in the previous section, low narrativity and playability backfire and in the end reduce the level of immediacy and immersion by revealing the artificiality of the narrative. If a narrative has a low level of narrativity and playability, the process of reception leads to a low degree of engagement, which raises awareness to the mediatedness, hence artificiality of the narrative. As a result, instead of increasing the level of immediacy and immersion of a narrative, decreasing to a minimum the narrator's manipulations of the story with the help of medium affordances decreases the level of immediacy.

Here are a few examples to show how the manipulation of temporality inflects immediacy. If a novel described each and every gesture of a character, coupled with the associated psycho-narration - the verbal representation of the often non-verbal thoughts of a character (Fludernik 2009, 80) -, as it was tried in experimental trends in novel writing such as the nouveau roman, the novel would become almost unreadable. Furthermore, its very status as narrative would be challenged and the novel would be more similar to a description (Herman 2009, 139). Or, if in a sandbox role-playing game such as Fallout $3^{6}$ one would have to literally spend eight hours while the playable character sleeps, or would have to literally traverse the Wasteland from one location to another in the absence of fast-travel option, the game would be boring and unplayable. Standing eight hours in front of the monitor will undoubtedly remind the gamer of the mediated nature of gaming experience.

In Silent Hill 2 we are faced with the attempt to conceal the narrator. In a video game, it is important to note that the narrator is controlled by both the player and the game designer - or, to be more precise, the game mechanics written by the game designer(s). In fact, the player controls the narrator only inasmuch as the game designer allows it. According to the logic of immediacy, in a video game, once the 
player internalizes the controls, he/she should no longer be aware of the fact that, besides the avatar, he/she is also controlling the narrator. When executing the video game, the console or computer becomes a storytelling device. You manipulate the device into conveying the story the way you want it to in the limits imposed by the game designer. When playing Silent Hill 2, you determine a particular unfolding of the plot and a particular presentation of the game's actual world, which means that you, the player, are also the narrator. You control James Sunderland, but you sometimes also control the camera angle from which you view James Sunderland. You also manipulate temporality by pausing the course of events when accessing James's inventory. Yet what the game tries to do is make the control of the narrator so natural that it becomes fully transparent, i.e. the player is no longer aware of the fact that he/she is also manipulating the audio-visual techno-narrative affordances.

But can the internalization of controls alone make the manipulations of the means used to represent the storyworld transparent? The answer is clearly no; the nature of these manipulations is also important. In order to make them transparent, the game remediates an already established medium, whose artificial means of manipulating and presenting the story have been naturalized by the global audience - the feature film.

\section{Remediation}

But first, what is remediation? Remediation is the process by which a medium incorporates another medium by means of imitating the latter's techno-narrative affordances with the purpose of attaining a higher degree of immediacy (Bolter and Grusin 1999, 45). For example, Silent Hill 2 remediates film by employing many cuts, fixed camera angles, continuity editing, extensive cut-scenes, and acting. To be sure, film and video games have always been intimately connected. Yet, Silent Hill 2 is far more filmic than most previous games. In fact, at the turn of the millennia, video games were becoming more and more cinematic - see Max Payne ${ }^{7}$ or Hitman: Codename $47 .^{8}$

The visual content of the first person shooters from the 1990s, such as Doom, ${ }^{9}$ Spear of Destiny ${ }^{10}$ and Quake, ${ }^{11}$ can very pertinently be described by using film language. Each level consisted of one long subjective camera shot. The duration

7 Remedy Entertainment. 2001. Max Payne. Europe: Gathering of Developers.

8 IO Interactive. 2000. Hitman: Codename 47. Europe: Eidos Interactive.

9 Id Software. 1993. Doom. Europe: GT Interactive.

10 Id Software. 1992. Spear of Destiny. US: Forgen Corporation.

11 Id Software. 1996. Quake. Europe: GT Interactive. 
of the shot was determined by the duration of the gameplay. Its only cuts were generated by the player's accessing the menu or pausing the game, but once the game was resumed the image was the exact one which had been rendered right before the pausing of the game. However, as far as the representation of the diegesis is concerned, classical first person shooters employ no in-level cuts. This would soon change in 1996 with the release of Resident Evil. ${ }^{12}$ While maintaining a focus on shooting, the game approaches gameplay from a new perspective. This time, the representation of the gameworld was more cinematic in that its walkthrough resembled very much the rolling of a film. If first person shooters employed only very few of the film's techno-narrative affordances (namely the subjective camera and the long shot), Resident Evil's remediation of film really took advantage of what the camera can do, and, consequently, the visual representation of the gameworld features many cuts, different camera angles, continuity editing, inlevel cutscenes and other cinematic elements. Silent Hill 2 pays tribute to Resident Evil's cinematic style by maintaining all the aforementioned characteristics, but adds new ones such as tracking shots that follow James Sunderland as he explores some parts of the gameworld. Furthermore, unlike Resident Evil and Resident Evil $2,{ }^{13}$ Silent Hill 2 allows the player to change the camera angle.

But how exactly does the extensive use of cinematic language enhance immediacy? With the advent of more advanced graphics, video games became more successful in imitating films. Film is a highly popular medium whose grammar has come to be culturally associated with immediacy. The spread of television and cinema around the globe has created a new type of literacy that is very unlikely for someone not living in a remote underdeveloped region not to master. Because film language is now the dominant immediacy code, it was natural for video games seeking a high degree of immediacy and immersion to want to employ film language and rise to the representational fidelity of the camera. What is more, around the year 2000 video games were still looking to achieve a certain cultural status. As Bolter and Grusin argue, it is often the case that new media seek to attain cultural capital and so they hope to borrow the prestige of older media by remediating them $(1999,69)$. Video games are no exception. By remediating film, video games have risen up the prestige ladder from what was initially deemed lowbrow to more middle- or even highbrow tastes.

But have third person video games such as Resident Evil and Silent Hill 2 really achieved a higher degree of immediacy by integrating more cinematic elements

12 Capcom. 1996. Resident Evil. US: Virgin Interactive.

13 Capcom. 1998. Resident Evil 2. US: Capcom. 
than previous first person action video games such as Doom or Quake games did? True as it may be that film is a medium whose representational capacities are regarded as being realistic and transparent, many of the shots recorded by the camera could not be perceived by a human being. For instance, the latest James Bond film, Spectre (Sam Mendes, 2015), begins with a tracking shot that follows the protagonist through a crowd at a festival into a hotel, then into a small elevator where he is accompanied by a female partner, then out of the elevator through the corridor into the room, then out the balcony for the camera to soar afterwards a couple of feet above James Bond's head only to then level down and provide an over-the-shoulder shot before cutting. Such a long shot is unnatural because, provided that one could actually sneak behind a person without losing sight of him/her for that long, the follower could not rise above floor level as the camera in Spectre was able to. By remediating film, video games started incorporating such unnatural shots that early first person shooters lacked. In a game such as Quake $2,{ }^{14}$ the shots you get through gameplay resemble humans' natural sight. We, as humans, have a continuous first person view of the world around us. This view is well replicated by first person shooters, with more recent games using enhanced graphics to render complex moving shadows according to in-game light sources, the avatar's own body parts, such as legs, arms and so on. In many first person shooters, when walking and running, the image trembles in order to mimic our eyesight when moving. In Silent Hill 2, we see James Sunderland from a third person perspective, sometimes from an angle in which we, as humans, could never position ourselves.

Taking this into account, it would be difficult to argue that, by remediating film, third person video games have attained a higher degree of immediacy than previous first person shooters. What can nevertheless be deduced is that these games make a shift from imitating natural eyesight, therefore a type of immediacy based on our natural technologically unmediated perception of the real world, to imitating a technological and cultural sight, namely the representational affordances of film, a medium with significant cultural prestige, whose technological capacities are culturally constructed as being realistic and transparent.

To sum up, this paper has been an attempt to construe immersion as the result of two gradient categories: interactivity and immediacy. Without losing focus of the interconnectedness of the two dimensions of immersion, I pursue an individual analysis of interactivity and immediacy. In the former case I argue that, although one could assume that the more freedom you have in a video game, the more

14 Id Software. 1997. Quake II. Europe: Activision. 
transparent the gaming experience becomes, actually - as I showed -, freedom of action and choice has to be limited in order to ensure a high degree of playability and narrativity for the video game. Similarly, by relying on recent approaches to the concept of narrator, I argue that, although the logic of immediacy would imply that the less the content of the narrative is manipulated by the narrator with the help of the medium's specific techno-narrative affordances, the more authentic, or real the narrative is regarded, the purposes of narrativity and playability make it compulsory that the content be manipulated so as to ensure the player's engagement. My last step was to inspect the relation between remediation and immediacy. By comparing first person shooters and third person shooters I highlight the different ways in which each of them attempt to achieve medium transparency: the former imitate natural eyesight, while the latter remediate film.

\section{References}

Aarseth, Espen J. 1997. Cybertext: Perspectives on Ergodic Literature. Baltimore, MD: Johns Hopkins University Press.

Bolter, J. David, and Grusin, Richard A. 1999. Remediation: Understanding New Media. Cambridge, MA: MIT Press.

Brooks, Peter. 1992 [1984] Reading for the Plot: Design and Intention in Narrative. New York: A.A. Knopf.

Calleja, Gordon. 2011. In-Game: From Immersion to Incorporation. Cambridge, MA: MIT Press.

Fludernik, Monika. 1993. The Fictions of Language and the Languages of Fiction: The Linguistic Representation of Speech and Consciousness. London: Routledge.

Fludernik, Monika. 1996. Towards a 'Natural' Narratology. London: Routledge. Fludernik, Monika. 2009. An Introduction to Narratology. London: Routledge. Herman, David. 2009. Basic Elements of Narrative. Chichester: Wiley-Blackwell. Herman, David. 2012. Narrative Theory: Core Concepts and Critical Debates. Columbus: Ohio State University Press.

Hogan, Patrick Colm. 2014. Emplotting a Storyworld in Drama: Selection, Time, and Construal in the Discourse of Hamlet. In Storyworlds accross Media: Toward a Media-Conscious Narratology, eds. Marie-Laure Ryan and Jan-Noel Thon, 50-66. Lincoln and London: University of Nebraska Press.

Hutcheon, Linda. 2006. A Theory of Adaptation. New York: Routledge. 
Jahn, Manfred. 2005. Narratology: A Guide to the Theory of Narrative. English Department, University of Cologne. http://www.uni-koeln.de/ ame02/pppn. htm. Last accessed 10. 01. 2016.

Juul, Jesper. 2014. On Absent Carrot Sticks: The Level of Abstraction in Video Games. In Storyworlds accross Media: Toward a Media-Conscious Narratology, eds. Marie-Laure Ryan and Jan-Noel Thon, 173-192. Lincoln and London: University of Nebraska Press.

Nae, Andrei. 2016. The Narrativization of Gameplay in the Survival Horror Video Games Silent Hill and Silent Hill 2. Narrative 2016 Conference, University of Amsterdam. The International Society for the Study of Narrative.

Prince, Gerald. 2008. Narrativehood, Narrativity, Narratability. In Theorizing Narrativity, eds. J. Pier \& J. Á. García Landa, 19-27. Berlin: de Gruyter. Ryan, Marie-Laure. 1991: Possible Worlds, Artificial Intelligence, and Narrative Theory. Bloomington: Indiana University Press.

Ryan, Marie-Laure. 2006: Avatars of Story. Minneapolis: University of Minnesota. Suits, Bernard. 1978. The Grasshopper - Games, Life and Utopia. Toronto, Buffalo, New York and London: University of Toronto. 